\title{
THE IMPACT OF SOCIAL MEDIA ADOPTION BY COMPANIES. DIGITAL TRANSFORMATION
}

\author{
Darius Daniel Onețiu* \\ West University of Timisoara, Romania \\ E-mail:darius.onetiu@gmail.com
}

(Received: March 2020; Accepted: May 2020; Published: June 2020)

\begin{abstract}
This article highlights the adoption of social media by organizations and its consequences on the company's performance. These topics of debate are becoming more and more common in the business environment. In fact, it is the main argument for which this paper relates the particularly important aspects of the adoption of social media (social networks) by organizations. In the following, important aspects that bring value to the organization, both by acquiring and by adopting social media in sales performance, have been structured. This research is built on a theoretical study, including as main terms of discussion: social media adoption and digital transformation. In the last part of the article, we have summarized and concluded these factors. We have identified how they can contribute to a more efficient orientation of sales performance, to increase the organizational management of the relationship and the connection between customers and the organization. Referring to the orientation towards "use of social networks" by organizations, we demonstrate that organizations are required to give high importance to understanding the organization's customers and, of course, a high degree of relational performance. Another factor encountered in this theoretical research is "digital transformation". We debated this topic in order to easily make the transition to the adoption of "social media" by organizations. Following the theoretical research, we can say that today, digital transformation has special importance in the organization and the fact that a strong link has been created among social media, reality management and performance in relational sales.
\end{abstract}

Keywords: social media, digital transformation, company’s performance.

JEL Codes: M31, M29, M30

*Corresponding author: Darius Daniel Onețiu. E-mail: darius.onetiu@gmail.com

Copyright $(2) 2020$ The Author(s). Published by VGWU Press

This is an Open Access article distributed under the terms of the Creative Commons BY 4.0 license (Creative Commons - Attribution 4.0 International - CC BY 4.0) which permits unrestricted use, distribution, and reproduction in any medium, provided the original author and source are credited.

83 Sciendo Studia Universitatis "Vasile Goldis" Arad. Economics Series Vol 30 Special Issue 2/2020 ISSN: 1584-2339; (online) ISSN: $2285-3065$

Web: publicatii.uvvg.ro/index.php/studiaeconomia. Pages 83-96 
Onetiu, D.D., (2020)

The impact of social media adoption by companies. Digital transformation

\section{I.1. Introduction}

This paper begins by reviewing the existing literature about the characteristics and effects of digital transformation, continuing with the use of social media in the relational sales process. Therefore, the key factors of the adoption of social networks will be identified, so that later in another research study it will be possible to build a conceptual model and conduct quantitative research based on it. Various methodologies adopted by organizations will be discussed. Analyzing the literature, with the help of research, in this article I will highlight theoretical and key elements of the adoption of social networks by companies.

The purpose of this study is to find out if social networks significantly affect sales processes and business to business sales performance, according to a theoretical basis. Following several research studies, it is specified that "in the literature, there is no academic study that measures the effects of social media and sales performance in a B2B context", this being stated in an article written by Rodriguez et al. (2012). Therefore, the current study makes some contributions. First, the study of social media and its use in the sales organization is an extension of the existing research and literature in the field of sales technologies. Second, we suggest that exists a link between social media and sales performance by creating opportunities and managing customer relationships - treated as two critical components of sales processes. Therefore, we approach the utility of social networks in a Business to Business framework.

The whole discussion of this article is built around the theory of existence, underlining the following concepts: digital transformation and the concept of social media. The concept of social media is seen from two perspectives: once as a theoretical basis for understanding and once as a description of the evolution in the field of sales technology. Then we discuss the development of our hypotheses, which focus on the behaviors of the sales process - the use of social media, creating opportunities, understanding customers, relationship management, performance in relational sales and company performance. We will apply and clarify all these hypotheses as I said above in another qualitative and quantitative research study. Therefore, in the next research study that I will perform, I will develop more detailed and apply these aspects with the help of the conceptual model. In this paper, I will only sketch the conceptual model I have prepared. The methodologies of this study are then shared and followed by the results. Finally, the conclusions of this research and the potential aspects of the research are presented. 
Onețiu, D.D., (2020)

The impact of social media adoption by companies. Digital transformation

2. Characteristics and effects of digital transformation. Social media - the factor of sales performance

\subsection{Digital transformation}

As we specified in the introduction of this article, this paper begins by transposing and defining the term digital transformation. This term is frequently used by organizations, but what does this actually imply and how does it influence the business environment? According to the specialized literature, the term "digital transformation" has been used to describe almost anything, from the development of a mobile website to the development of a social media strategy. "But reality tells us that the digital transformation must involve much more than the final product". (Chahal, 2016). Thom Groot states: "Digital is at the heart of the business and in his opinion is a reflection of the fact that customer behavior is changing more and more. The speed of digitization has accelerated this change, and therefore companies need to be able to change quickly to respond to customer behavior. "Basically, digital transformation is the key factor in the adaptability of companies to customers. Both in current practice and among companies, in order to build the executive board of a company and to carry out digital transformation projects requires the contribution of the entire business, or rather the contribution of the entire team: from the highest leaders positions to those in the Board of Directors. All are important for the plan to be successful. It's not about doing 'digital marketing', it's about doing effective marketing in a digital world" (Chahal, 2016). In order for organizations to achieve a series of objectives, we will list some "strategic objectives encountered inside any organization in the era of digital disruption", according to www.star-storge.ro:

- Facilitating innovation.

- Improve the user experience, whether we are talking about your customers or employees.

- Excellent execution and on-demand of the business processes by eliminating complexity.

- Minimizing risks and exposure of the company.

Among the most important and tangible benefits that a company can get from digital transformation are the following:

- simplicity;

- transparency;

- efficiency.

Another interesting topic we can approach in our work is the "learning curve of new technologies". This approach implies, according to www.imworld.ro, that "it is important for every employee of the company to understand that the result of the transformation must be that of simplifying the work. Because no other option 
Onetiu, D.D., (2020)

The impact of social media adoption by companies. Digital transformation

should be accepted if the digital transformation only leads to the multiplication of difficulties in the daily routine of an employee. Otherwise, this could mean that the whole process has been implemented incorrectly". From here we can say that there is also the need for each employee to be actively involved in the process, not just waiting to see what changes will occur in his department. Each individual inside the organization must be an agent of change by clearly exposing the problems that technology can bring and believes that they can be simplified, intervening in the need for transparency at all levels of the organization. It is easy to understand that streamlining processes and improving transparency in communication naturally leads to increased profit.

So, we can say that a digital transformation is no longer an option, it is becoming a necessity. Digital transformation involves an internal and external process of the metamorphosis of companies and their employees. As technologies develop at a rapid pace, companies of all sizes need to understand that only by keeping up with new changes can they maintain their competitiveness and market relevance. Implementing technologies such as cloud computing, artificial intelligence, the Internet of Things or Big Data Analytics within an organization will improve its long-term performance. Digital transformation is not just about the technology itself, but also about the supply between technology and the human factor, adapted to these new changes.

Once a digital transformation is adopted by a company, it can improve the following:

\section{a) Analysis and understanding the customers}

It all starts with a better understanding of the company's customers and the ability to offer them the best services. However, the most detailed analysis of customers can be obtained only through the appropriate digital tools, which allow obtaining relevant data about them. Here we can talk about Marketing Automation tools, CRM (Customer Relationship Management) or even chat-bots that approach customers once they arrive on the website and offer them real-time assistance.

\section{b) Development and innovation of products and services}

Digitization certainly accelerates the process of developing the products and services offered. Some time ago, the product design and design stage was largely focused on a traditional approach and came in response to market research results. However, if we refer to the idea expressed in the previous point, it is clear that by researching customers using digital tools, through a more detailed and real-time analysis of their behavior during all stages of the purchasing process, it is possible to create products and services perfectly tailored to consumer needs. Moreover, through digital transformation, product development can benefit from new advantages, such as continuous delivery or automatic testing. Here we also refer to the implementation of "agile" software development methodologies, which require

86 Studia Universitatis "Vasile Goldis" Arad. Economics Series Vol 30 Special Issue 2/2020 ISSN: 1584-2339; (online) ISSN: $2285-3065$

Web: publicatii.uvvg.ro/index.php/studiaeconomia. Pages 83-96 
Onețiu, D.D., (2020)

The impact of social media adoption by companies. Digital transformation

a quick and flexible response to change and early and continuous improvement in order to satisfy customers.

\section{c) Interaction with employees and their productivity}

According to the website www.blog.webland.ro, "the employees of a company will be the first to feel the changes brought about by the digital transformation. However, according to some studies, they can also be a barrier to digital transformation, due to a possible lack of digital skills. Therefore, it is necessary for a company to ensure that employees will receive appropriate training to facilitate their transition to new technologies". However, once this moment is over, collaboration and communication between employees will certainly be improved, and their productivity will increase.

In what ways can the employee experience be concretely improved? Companies now have developed digital tools, starting with software applications dedicated to the HR department, ERP (Enterprise Relationship Management) applications, CRM and continuing with internal social media tools, instant messaging or platforms for virtual meetings. At the same time, a new trend seems to be the use of wearables. Such examples include smartwatches (through which employees can check their email, messages or calendar and communicate in real time), smart glasses (to increase security, the company being in this way able to identify what information was accessed, when and by who) or smart bracelets (for measuring, for example, the pulse, the number of steps taken in a day or the number of calories consumed, in order to motivate employees to approach a healthy lifestyle).

Recently, new marketing trends are emerging in the retail industry, "the integrated development of digital technology and the gradual creation of the digital society" (Zhu \& Gao, 2019). The author concludes in his article: "If retail businesses do not want to be abandoned by consumers, they need to see new conceptual marketing models to efficiently improve their core competitiveness. Sustainable development among merchants can be achieved by using new technologies, changing the traditional marketing method and accurately collecting precision marketing resources for valuable customers and establishing a new conceptual model" (Zhu \& Gao, 2019).

\subsection{Social media}

Nowadays, business people tend to use social media marketing to raise awareness and promote their brands to both current and potential customers. The main point of sharing information through social media marketing is about creating content to attract more consumers. "Social media content marketing (SMCM) also plays an important role in conveying effective information to consumers" (Ahmad et al., 2016). There are few indicators for measuring the "health of the brand", such as time on the site, repeat visitors on the site, social likes, subscriptions and rejection 
Onețiu, D.D., (2020)

The impact of social media adoption by companies. Digital transformation

rates. There are still limited studies on the impact of social media marketing (SMCM) content on "brand health".

The concept of social media is increasingly met and debated by more and more researchers. This is due to the fact that researchers and practitioners are desirous to understand its potential to support brands, sales, customer service and product development, both new and already on the market. Most of the time, consumers perceive "social media" as more reliable than any other information sponsored by organizations and therefore increasingly turn to social media to get more data about products and services. Taking advantage of the popularity of these social networks and their perceived credibility in the market, more and more organizations have an important presence on social media to attract customers with their products and brands. In other words, empirical evidence suggests that social media adoption can bring significant benefits to organizations. It indicates, in particular, that social media can generate higher buying attitudes and intentions than traditional digital media. Moreover, social media and social networking sites have been widely used as a marketing communication tool, due to their potential to spread viral and WOM-generating messages. "Inside the organizations, media relations have the potential to create capabilities that can be turned into useful resources, which in turn will result in greater competitive advantage and performance" (Wohn et al., 2013).

Considering the study of "Our World in Data" from September 18, 2019, published on the website https://ourworldindata.org/rise-of-social-media entitled "The rise of social media" by Esteban Ortiz-Ospina, we can see why social networks have such a big impact on the business environment and on sales performance. In this study, Esteban Ortiz-Ospina states that: Facebook, the largest social networking platform in the world, has 2.4 billion users. Other social networking platforms, including Youtube and Whatsapp, also have over a billion users each. These numbers are huge - there are 7.7 billion people in the world and at least 3.5 billion people online. This means that social media platforms are used by one in three people in the world and more than two-thirds of all internet users. Social media has changed the world. The rapid and widespread adoption of these technologies is changing the way we find partners, how we access news information and how we organize to demand political change. In the chart below you can see the evolution of social media over the whole world.

Due to the potential of the social networks mentioned above and their need for marketing departments to capture the value generated by such channels, marketers tend not to evaluate their effectiveness.

The existing literature suggests that traditional environments are not suitable for this dynamic and highly interactive environment, which could explain the tendency of traders not to evaluate their effectiveness. Research on the use of social media

88 Sciendo Studia Universitatis "Vasile Goldis" Arad. Economics Series Vol 30 Special Issue 2/2020 ISSN: 1584-2339; (online) ISSN: $2285-3065$

Web: publicatii.uvvg.ro/index.php/studiaeconomia. Pages 83-96 
Onetiu, D.D., (2020)

The impact of social media adoption by companies. Digital transformation

focuses largely on business to consumer contexts. However, recently, the empirical investigation has started to address social media marketing in industrial environments. Following existing evidence highlighting the significant role of the Internet in business-to-business contexts, business-to-business researchers have begun to appreciate the importance of these tools, mainly in attracting new customers and cultivating relationships with existing buyers. This is in line with the literature on the role of the Internet as a tool to facilitate the development of relationships. "Business to business organizations can implement strategies when using the Internet, more exactly three strategic values: the information-rich strategy, the relational exchange and the common learning strategy. Consistent with the above evidence, it is clear that social media marketing is as relevant and valuable in the business to business context as it is in the business to consumer context, although the adoption rate has been relatively slower for business to business organizations" (Wohn et al., 2013).

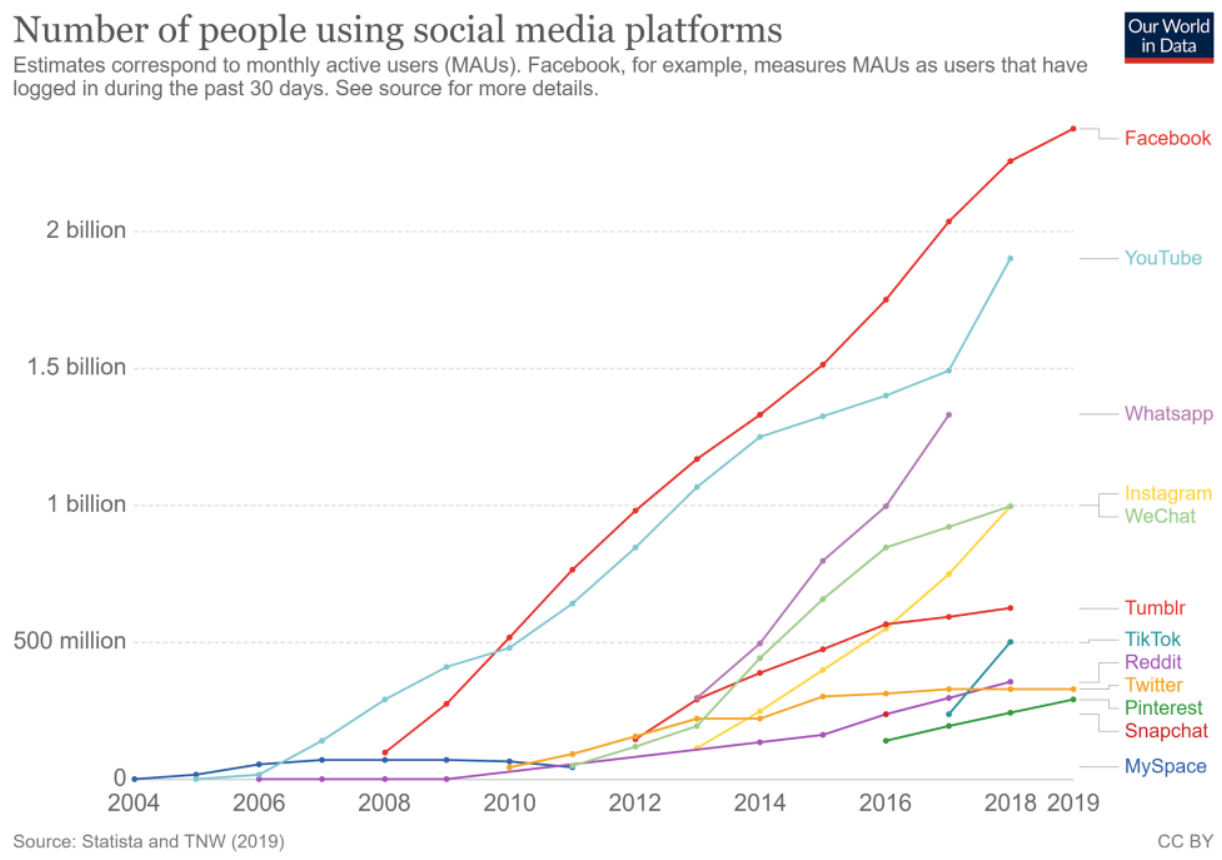

Figure 1 Number of people using social media platforms

"Social media is becoming omnipresent and needs to be managed like all other forms of media that organizations hire to achieve their goals" (Peters et al., 2013). 
Onetiu, D.D., (2020)

The impact of social media adoption by companies. Digital transformation

However, social media is fundamentally different from any traditional or other online media due to the structure of the social network and the egalitarian nature. These differences require a distinct measurement approach as a necessary condition for proper analysis and subsequent management.

\subsection{Adoption of social media by Business to Business organizations}

Companies believe that it is necessary to change their approach to customer relationship management (CRM) and develop new marketing capabilities that facilitate customer satisfaction. The purpose of this study is to examine how the use of social media can help companies develop new CRM capabilities and then improve their marketing adoption strategies and business performance. "We suggest that social CRM capability is essential when companies combine social media into marketing strategies to improve customer engagement and strong performance" (Wang \& Fred Miao, 2017).

The specialists conducted a study that contributes to the current lack of knowledge about the potential of social media as a marketing tool in the industrial environment, focusing on the factors that determine the adoption of social media by B2B organizations. A conceptual model based on acceptable technology theory and resource theory is developed and tested using quantitative data from B2B organizations in the UK. Technological developments have introduced significant changes in the way organizations interact with existing and potential customers. The advent of Web 2.0 technologies and the increasing popularity of social media has allowed a more direct and interactive form of communication, in which users can easily share and digest information on the Internet. Individuals tend to spend more time on social networking sites than on any other category of sites, while PC users use $17 \%$ of their time just on Facebook.

"Appreciating the popularity of social networks, organizations are increasing their presence on multiple social platforms. 26\% of the American consumers suggest that they accept ads from social networks that are based on their profile information and are in line with evidence illustrating the significant benefits of increased brand involvement, social networking sites are perceived as a tool for vital marketing" (Wohn et al., 2013).

"Some business to business companies, especially traditional industrial companies, even today emphasize the fact that social media is only useful in the business to the consumer sector" (Jussila et al., 2014). Taking into consideration this statement for about 6 years, I believe that today things have changed and B to B companies have changed their perception of social media. We can observe this from the current business environments and from the fact that more and more employees inside the companies are using more and more social networks to fulfill their tasks.

90 Sciendo Studia Universitatis "Vasile Goldis" Arad. Economics Series Vol 30 Special Issue 2/2020 ISSN: 1584-2339; (online) ISSN: $2285-3065$

Web: publicatii.uvvg.ro/index.php/studiaeconomia. Pages 83-96 
Onețiu, D.D., (2020)

The impact of social media adoption by companies. Digital transformation

\section{Social media impact on sales performance}

\subsection{Adoption of the new technologies in the sales}

We discover that the implementation of social media technology in a company's marketing strategy has been adopted by the sales forces. Creating and sharing content, followed by building a network of contacts are the main factors behind a social media database. "The use of social networks (e.g. LinkedIn and Twitter) to reach business-to-business customers is a relatively new phenomenon, with essentially unknown performance results. Data were collected from 1,699 businessto-business vendors in more than 25 different industries. Using the modeling of the structural equation, the results claim that social media has a positive relationship with sales processes (creating opportunities and managing relationships) and relational sales performance" (Rodriguez et al., 2012).

B2B sales face a number of challenges in today's environment, such as: increased competition, a slowing global economy, product customization and lead generation. As sales organizations lose customers each year for a variety of reasons, there is a constant need to expand the customer base by building a sales strategy. One of the constant obstacles in B2B sales is finding the right type of customers, through prospecting efforts and then discovering the decision-makers within the network of external stakeholders. "A growing challenge for B2B sales is the implementation of technology and its impact on the sales process. Current research has tested the influence of sales technologies on customer relationship development and improved internal administrative performance. Other research has shown that CRM technology has helped sales professionals improve closing rates and generate revenue faster" (Rodriguez et al., 2012). Sales technology, in the form of social support, has been used by organizations to improve the performance of sales tasks. "With the evolution of the Internet and Web 2.0, the use of social media in the B2B environment has advanced from a simple tool used to connect with friends, to an important platform to reach new buyers and to develop deeper relationships with customers" (Rodriguez et al., 2012).

Social capital theory provides a basis for understanding the impact and importance of social media for organizations. Social capital theory is a sociological concept that refers to the connections inside and between social networks. This framework helps to understand how human interaction creates opportunities to influence relationships, for solutions in the business community. People who join or create these networks enjoy higher rates of return because they are informed about opportunities and probably contribute to their creation. In the context of B2B sales, developing prospects and customer acquisition are two central themes of sales performance. This paper argues that firms can increase social capital by systematically mobilizing social networks to expand networks and therefore 
Onetiu, D.D., (2020)

The impact of social media adoption by companies. Digital transformation

increase performance within their firms. Social capital exists at an individual and collective level. Therefore, power in share capital can shorten trading periods due to the social connections between knowledge seekers and knowledge owners. In essence, prior social connectivity between buyers and sellers can affect results based on network familiarity and trust, exactly the social capital between the parties involved. It is concluded that an increase in share capital allows for less costly collaborative transactions between stakeholders. "Value, mutual trust and reciprocity increase the chances of mutually beneficial exchange by reducing the risk of failed transactions" (Rodriguez et al., 2012).

Some sales firms have invested billions of dollars in technology to make their sales forces more efficient in managing the sales process and building stronger relationships with buyers. Emphasis was placed on the use of sales technologies due to several technological challenges within sales firms: high failure rates, low user acceptance and high implementation costs. "Some sales-focused research on technological innovation claims that there is a positive relationship between use and performance. The assumption is that increased use of technology is a desirable behavior and involves better performance. "Before discussing the influence of social media in the B2B environment, we first analyze the evolution of social media in the context of CRM" (Rodriguez et al., 2012).

Marketing practices are increasingly affected by the implementation of new technologies, creating opportunities and threats for marketing practitioners. The impact of the Internet on the structure of the market or the new business paradigms have been more and more often encountered in the specialized literature. "New technologies act as internal agents of change, sometimes forcing companies to adapt to new processes. And these, in turn, disrupt existing hierarchies" (Tapp \& Hughes, 2004). The marketing objective must be oriented towards internal management, facilitating market orientation at the level of the entire organization.

\subsection{Sales performance}

Previous research has argued that sales technology can enable sales professionals to improve sales performance, such as efficiency with administrative and relationship tasks and the efficiency of the sales process. Sales performance is defined as "the behavior assessed in terms of its contribution to the organization's objectives". In the current study, performance is divided into two categories that conceptualize the two areas of sales performance constructions: relationship performance and results-based performance. Relationship sales performance is based on the relational measurement of sales performance, which focuses on behaviors that strengthen the relationship between buyers and sellers. The results of sales performance measures are an important aspect in measuring sales performance and are reflected in the achievement of quotas, the increase in the

92 Sciendo Studia Universitatis "Vasile Goldis" Arad. Economics Series Vol 30 Special Issue 2/2020 ISSN: 1584-2339; (online) ISSN: $2285-3065$

Web: publicatii.uvvg.ro/index.php/studiaeconomia. Pages 83-96 
Onețiu, D.D., (2020)

The impact of social media adoption by companies. Digital transformation

average billing size, the increase in sales productivity and the overall revenue gain. Superior sales performance of relationships should subsequently lead to sales performance based on superior results. Previous studies argue that relational sales behaviors with customers are a "key aspect of outward-looking sales performance". Although these two aspects of performance are expected to be correlated, in theory, they are different aspects of sales performance.

Social media is used to increase the social capital of a company; it can influence both relationship-based aspects and results based on sales performance. For example, relationships developed through the social media network can increase the number of qualified leads and increase relationships with current customers, which could lead to an increase in customer retention. Companies that use social media technology can communicate with customers who feel comfortable using social media to search for information about products or services that meet their business needs. Using social media can help organizations better provide current customers with value-added content distribution or more effective communication. "Social media should also affect results based on sales performance" (Rodriguez et al., 2012).

"In order to be able to evaluate the return on investment of implementing new sales technologies, sales managers need a practical means" (Hunter \& Perreault Jr., 2013). Including sales automation and sales-based customer, relationship management systems can be considered. The technological orientation of a salesperson has a direct impact on the performance of the internal role and affects the performance with the customers through a double average mechanism that involves the efficient use of information and intelligent sales behaviors (planning and adaptive sales). Sales managers can influence the orientation of sales technology by providing better internal technology support, taking into account the technological orientation together with the approval of the technology by the customer and understanding the probability of negative effects through the experience of a salesperson.

Market orientation is the center of modern marketing thinking and practices. "Although research has shown that market orientation contributes to strong performance through innovation, there is no understanding of how the dimensions of customer orientation, competitor orientation and inter-functional coordination can have differential effects on innovation, especially in the context of sale. The effect of sales force creativity on performance is fully mediated by the implementation of innovation, which can be strengthened by an innovative organizational culture" (Wang \& Fred Miao, 2015).

\section{The conceptual model. Future research}

The figure below shows the conceptual model that I will apply according to the 
Onețiu, D.D., (2020)

The impact of social media adoption by companies. Digital transformation

theoretical basis built in this article. A case study will be conducted based on a questionnaire applied to a sample of at least 50 companies from different fields of activity.

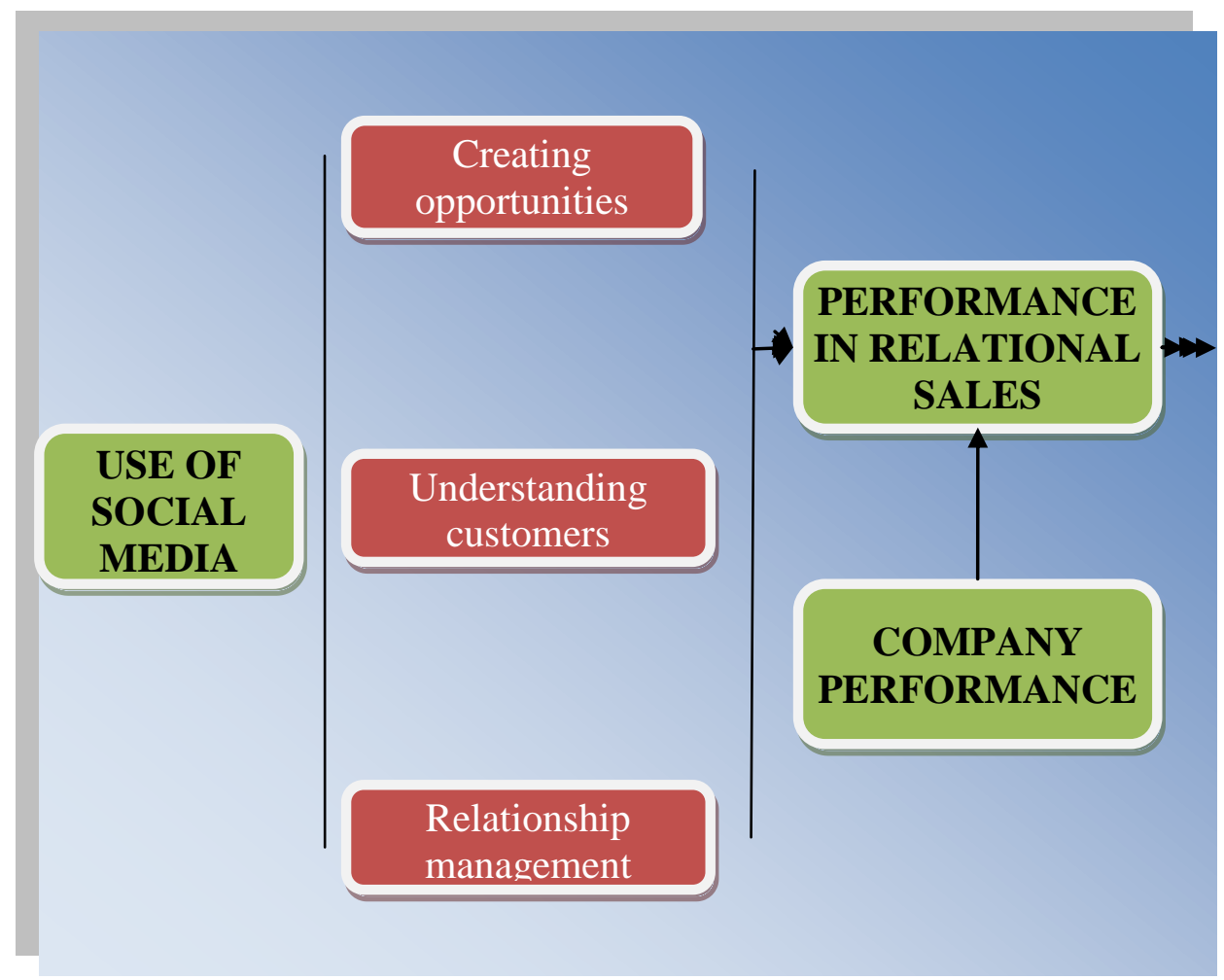

Figure 2 Conceptual model

Starting from the explanation of this model, the concept (logical schemes) will be implemented and studied the effect of social media adoption on the company's performance. In order to be able to prove this, it is necessary to identify what is the effect of social media on creating opportunities, understanding consumers and last but not least on the managerial relationship. After identifying the social media effect on the 3 factors listed above, we will identify the effect on performance in relational sales and then demonstrate that all these factors lead to the company's performance. 
Onețiu, D.D., (2020)

The impact of social media adoption by companies. Digital transformation

\section{Conclusions}

In conclusion, we accentuate that building a high-quality relationship with customers is beneficial for marketing. Marketers are also aware of the importance of creating satisfied, loyal customers who will tell others about their positive experiences. In general, the inclusion of social media communications in the marketing efforts of a company's relationships has many advantages for marketing. Therefore, the importance of technology in customer relationship management has increased significantly, especially with the advent of innovations such as cloud computing technology and web-based technology. One of the most popular topics in both academic research and business discussions has been the use of customer relationship technology (CRM) to increase business and sales productivity through the continuous development of customer relationships. A new phenomenon in understanding the needs of buyers and reaching new customers is social media marketing. To streamline the sales process, organizations capture data from tools such as LinkedIn, Facebook and blogs to try to integrate information into their sales process. In order to increase the value of the client, the organizations must extract the value of the technology and build a framework of applied processes.

Recommendations and future directions may be provided following the quantitative and qualitative study according to the conceptual model presented in this current study.

\section{Acknowledgments}

The author thanks the anonymous reviewers and editor for their valuable contribution.

\section{Funding}

This work was co-financed from the European Social Fund through Operational Programme Human Capital 2014-2020, project number POCU/380/6/13/125015 "Development of entrepreneurial skills for doctoral students and postdoctoral researchers in the field of economic sciences".

\section{Author Contributions}

The entire article was written by Darius Onețiu.

\section{Disclosure Statement}

The author has not any competing financial, professional, or personal interests from other parties.

\section{References}

1. Ahmad, N.S., Musa, R., Harun, M.H.M., (2016), The Impact of Social Media Content Marketing (SMCM) towards Brand Health; Procedia Economics and 
Onetiu, D.D., (2020)

The impact of social media adoption by companies. Digital transformation

Finance, vol. 37, pp. 331-336

2. Chahal, M., (2016), The meaning of digital transformation, Marketing Week, April, pp. 16-20

3. Gray, P., El Sawy, O.A., Asper, G., Thordarson, M., (2013), Realizing Strategic Value Through Center-Edge Digital Transformation in Consumer-Centric Industries, MIS Quarterly Executive, vol. 12(1), pp. 115-117

4. Hunter, G.K., Perreault Jr., W.D., (2013), Sales Technology Orientation, Information Effectiveness, and Sales Performance, Journal of Personal Selling \& Sales Management, vol. 26(2), pp. 95-113

5. Jussila, J.J., Kärkkäinen, H., Aramo-Immonen, H., (2014), Social media utilization in business-to-business relationships of technology industry firms, Computers in Human Behavior, vol. 30, pp. 606-613

6. Peters, K., Chen, Y., Kaplan, A.M., Ognibeni, B., Pauwels, K., (2013), Social Media Metrics - A Framework and Guidelines for Managing Social Media, Journal of Interactive Marketing, vol. 27(4), pp. 281-298

7. Rodriguez, M., Peterson, R.M., Krishnan, V., (2012), Social Media's Influence on Business-to-Business Sales Performance, Journal of Personal Selling \& Sales Management, vol. 32(3), pp. 365-378

8. Tapp, A., Hughes T., (2004), New Technology and the Changing Role of Marketing, Marketing Intelligence \& Planning, vol. 22(3), pp. 284-296

9. Wang, G., Fred Miao, C., (2015), Effects of Sales Force Market Orientation on Creativity, Innovation Implementation, and Sales Performance, Journal of Business Research, vol. 68(11), pp. 2374-2382

10. Wang, Z., Kim, H.G., (2017), Can Social Media Marketing Improve Customer Relationship Capabilities and Firm Performance? Dynamic Capability Perspective, Journal of Interacting Marketing, vol. 39(August), pp. 15-26

11. Wohn, D.Y., Ellison, N.B., Khan, M.L., Fewins-Bliss, R., Gray, R., (2013), The role of social media in shaping first-generation high school students' college aspirations: A social capital lens, Computers \& Education, vol. 63, 424-436

12. Zhu, G., Gao, X., (2019), The Digital Sales Transformation featured by Precise Retail Marketing Strategy in China, Journal of Accounting \& Marketing, vol. 8(1), pp. 1-4

13. https://ourworldindata.org/rise-of-social-media

14. www.star-storage.ro

15. www.imworld.ro

16. www.blog.webland.ro 